
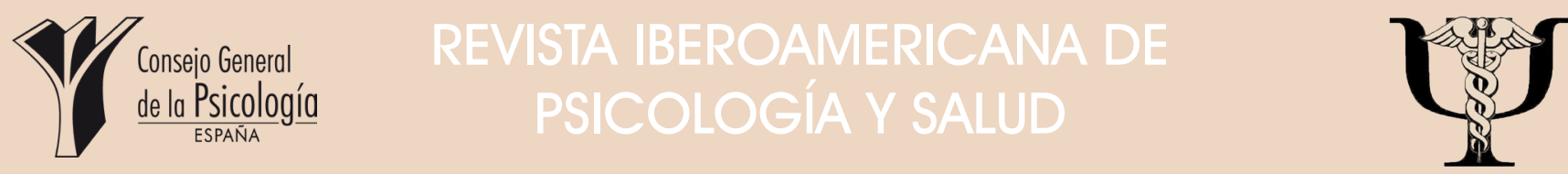

Revista Oficial de la Federación Iberoamericana de Asociaciones de Psicología (FIAP)

[Official Journal of the Latin-American Federation of Psychological Associations]

\title{
Efficacy of an internet-based psychological treatment for agoraphobia with minimal therapist contact
}

\author{
Wenceslao Peñate ${ }^{*}$, María José Roca-Sánchez ${ }^{2}$, Carmen T. Pitti $^{3}$, María Luz Villaverde $^{4}$, \\ Juan Manuel Bethencourt' ${ }^{1}$, Yolanda Álvarez-Pérez ${ }^{1}$, Juan de la Fuente ${ }^{5}$ \& Ramón Gracia ${ }^{6}$
}

'Dto. Psicología Clínica, Psicobiología y Metodología, Universidad de La Laguna (Spain).

Instituto de Biotecnología, Universidad de La Laguna (Spain).

${ }^{3}$ Servicio Canario de la Salud, Gobierno de Canarias (Spain).

${ }^{4}$ Escuela Universitaria de Enfermería y Fisioterapia (Spain).

${ }^{5}$ Servicio de Psiquiatría, Hospital Universitaro Na Sra. de la Candelaria, Gobierno de Canarias (Spain).

${ }^{6}$ Dto. Medicina Interna, Dermatología y Psiquiatría, Universidad de La Laguna (Spain).

- Received: 10 - January- 2017 . Accepted: 23 - March - 2017 . Avaliable online: 25 - April - 2017

ABSTRACT. This study deals with the efficacy of an Internet-based computer therapy compared with an in-person cognitive-behavioral therapy, in the treatment of agoraphobia. Patients in the Internet group only had minimal initial contact with a therapist. The sample was composed of 44 adult patients with a diagnosis of agoraphobia. The Internet group and in-person groups underwent an 11 -session intervention program. Agoraphobic cognitions, body sensations, social fear (as mobility test), and depression level were used as outcome measures. Results showed higher attrition rates in the Internet group. The in-person group exhibited improvements in all dependent measures, with moderate effect sizes ( 0.63 to 0.77 cohen's $d$ ). The Internet group showed improvements in body sensations and depression level (moderate effect sizes). Intergroup comparisons showed a higher efficacy of in-person therapy, with moderate to large effect sizes $\left(\eta^{2}=0.15\right.$ to 0.40$)$. After the intervention, the Internet group exhibited better results than the control group and comparable results to the in-person group in body sensations, social fears/mobility, and depression level. These results are discussed considering the limited extent of internet-based therapy.

KEYWORDS: Internet, Telehealth, Cognitive Behavior Therapy, Agoraphobia, Adults.

Eficacia de un programa de tratamiento para la agorafobia vía internet con contacto mínimo con un terapeuta.

RESUMEN. Este estudio trata de la eficacia de un tratamiento cognitivo-conductual vía internet para la agorafobia con un tratamiento cara a cara. Los pacientes en el grupo de internet sólo tuvieron un contacto inicial con un terapeuta. La muestra estuvo compuesta por 44 pacientes con un diagnóstico de agorafobia. Los grupos de internet y cara a cara recibieron un programa de tratamiento de 11 sesiones. Como medidas de resultados se utilizaron las cogniciones agorafóbicas, las sensaciones corporales, fobia social (como test de movilida d) y el nivel de depresión. El grupo de tratamiento cara a cara mostró mejorías en todas las medidas, con tamaños del efecto moderados ( $d$ de cohen: 0,63 a 0,77). El grupo de internet mostró mejorías en sensaciones corporales y depresión (también con tamaños moderados). Las comparaciones intergrupos mostraron una mayor eficacia del grupo cara a cara, con tamaños del efecto de moderados a grandes $\left(\eta^{2}=0,15\right.$ a 0,40). El grupo de internet mostró mejores resultados que el grupo control, y resultados comparables con el grupo cara a cara en sensaciones corporales, miedos sociales/movilidad y nivel de depresión. Estos resultados se discuten en relación con el alcance limitado de las terapias vía internet.

PALABRAS CLAVE: Internet, Telesalud, Terapia Cognitivo Conductual, Agorafobia, Adultos.

*Correspondence: Wenceslao Peñate Castro.

Dto. Psicología Clínica, Psicobiología y Metodología, Universidad de La Laguna.

Postcode: 38200, La Laguna (Spain).

E-mail:wpenate@ull.es

(c) 2017 Sociedad Universitaria de Investigación en Psicología y Salud. Published by (C) 2017 Sociedad Universitaria de Investigación en Psicología y Salud. Published by org/licencias/by-nc-nd/4.0/).

Citar como/Cite as: Peñate, W., Roca, M. J., Pitti, C. T. Villaverde, M. L., Bethencourt, J. M., Álvarez, Y., de la Fuente, J. \& Gracia, R. (2017). Efficacy of an Bethencourt, J. M., Álvarez, Y., de la Fuente, J. \& Gracia, R. (2017). Efficacy of an
internet-based psychological treatment for agoraphobia with minimal therapist internet-based psychological treatment for agoraphobia with minimal therapist
contact. Revista lberoamericana de Psicología y Salud, 8(2), 85-95, https://doi.org/10.23923/. rips.2017.08.008
Today there are no doubts about as Internet represents a fruitful and versatile resource for psychology across a range of fields, such as mental health practice, education, social issues, research, and many others (Krupinski \& Weinstein, 2014; Kyrios \& Thomas, 2014), 
though its use are not free from psychological problems (Moral \& Suárez, 2016). One of the most frequent applications of Internet in mental health is the delivery of psychological treatment (Baumeister, Reichler, Munzinger, \& Lin, 2014). As other technologies have been used (i.e., telephone; Vázquez, Torres, Blanco, Otero, \& Hermida, 2015), Internet computer-based treatments (ICTs) represent an alternative to in-person traditional psychological treatment. ICT programs usually include an explanation of the target problem (e.g., anxiety, phobias, depression, eating disorders), the detection of symptoms related to the disorder/problem, and components of a therapeutic program.

From a practical point of view, several advantages of ICTs have been highlighted (Newman, Szkodny, Llera, \& Przeworski, 2011; Peñate, 2012; Peñate, Roca-Sánchez, \& PinoSedeño, 2014). Such advantages include the possibility for patients of accessing mental health services when such services are not otherwise available and the ability to treat patients with physical mobility problems or geographical difficulties. Moreover, ICT programs are usually accessible around the clock, any day of the week, and can be a good option for patients for whom the fact of having a mental disorder is a stigma.

A special advantage of ICTs is that sometimes they are a treatment alternative because of the symptoms of specific mental disorders. This is the case of agoraphobia, an anxiety disorder that is relatively frequent among the population, with prevalence rates as high as 6\% (Alonso et al., 2004; Kessler, Petukhova, Sampson, Zaslavsky, \& Wittchen, 2012). According to its clinical description, agoraphobia is mainly characterized by disproportionate and disabling embarrassment and/or fear in the face of certain external stimuli (e.g. crowds, open spaces, venturing far from home, closed spaces, being alone) and internal stimuli (i.e. feelings of anxiety-panic). These feelings lead individuals with agoraphobia to avoid such stimuli or escape from them. In severe courses of this condition, the fear of experiencing symptoms of anxiety restricts patients' mobility and patients end up staying at home as a 'strategy' to avoid such symptoms (Wittchen, Gloster, Beesdo-Baum, Fava, \& Craske, 2010). Consequently, ICTs can be a first-choice treatment for these patients not because such treatments are better but because patients can receive treatment via the Internet without having to leave their homes.

Several systematic reviews and metaanalyses have been conducted to determine the efficacy of ICTs, including meta-reviews (Foroushani, Schneider, \& Assareh, 2011 ; Peñate \& Fumero, 2016). Although such reviews do not always reach the same conclusions, they share some common features: (i) ICTs are effective compared to no-treatment control groups; (ii) the efficacy of ICTs is improved by wellstructured and comprehensive programs based on cognitive and behavioral approaches; and (iii) contact with a therapist (i.e. 'guided $\mid \mathrm{CT}^{\prime}$ ): treatments are more effective when the patient can have some contact with a therapist (whether programmed or not). Specifically, ICTs' studies for panic disorder (with or without agoraphobia), attain similar improvements, even when ITCs are compared with in-person treatments, based on well-designed cognitive behavior therapies (Bergström et al., 2010; Carlbring et al., 2005; Kiropoulos et al., 2008; Klein, Richards, \& Austin, 2006).

However, ICTs also have disadvantages. Again, systematic reviews and meta-analyses (Andersson, Cuijpers, Carlbring, Riper, \& Hedman, 2014; Andersson \& Titov, 2014; Davies, Morriss, \& Glazebrook, 2014; Newman et al., 2011 ; Richards \& Richardson, 2012; van Ballegooijen et al., 2014), have shown substantial heterogeneity in the theoretical orientation, components, access, and presentation of ICTs. This diversity applies to the types of psychological disorder addressed, the therapy modality and components used, the procedure and methods followed for delivering the therapy, and the number of sessions provided. This heterogeneity can also be observed in the quality of the Internet presentation and acceptability (e.g. access, use of video, audio, cartoons, avatars, text).

The following methodological concerns can be drawn from these conclusions: (i) ICTs are seldom compared to in-person therapy (Andersson \& Titov, 2014). This is relevant because, when ICTs are compared to the absence of treatment, their efficacy can be attributed to other factors (e.g., the role of novelty); (ii) when an in-person therapy group is present, it is not usually a comparable matched group (e.g. same therapy, contents, number of sessions (Andersson \& Titov, 2014; Newman 
et al., 2011); and (iii) 'guided ICT' can pose a methodological and epistemological problem (Baumeister et al., 2014; Newman et al., 2011 ; van Ballegooijen et al., 2014): if the efficacy of ICTs rises in direct proportion with contact between the patient and the therapist, an increase in contact time can turn an ICT into a direct therapy in practice and make it lose its nature.

In light of the above and in order to overcome such methodological concerns, the aim of this study was to test the efficacy of an ICT by comparing an ICT treatment group to a matched in-person cognitive-behavioral treatment group and to a no-treatment group. The ICT used was designed for the psychological treatment of agoraphobia (www.doctoragora. $\mathrm{com} /$ demo) with minimal therapist contact (this minimal contact consisted in an initial one-hour interview to verify the diagnosis and to provide information about the access to website).

\section{METHOD}

\section{- PARTICIPANTS}

The sample was recruited using two procedures: participants were referred from mental health community units and from the Canary Islands University Hospital, in Spain. Inclusion criteria for participants were meeting the International Classification of Diseases (ICD-10) criteria for the diagnosis of agoraphobia (World Health Organization, WHO, 1992), with or without panic disorder (F40.01, F40.00).

Exclusion criteria were psychosis, bipolar disorders, personality disorders, and other anxiety disorders where agoraphobia disorder was a secondary diagnosis. All participants signed a consent form approved by the institutional ethics committee of the Canary Islands University Hospital.

There was a semi-random assignment to experimental groups. Specifically, patients who had greater difficulties with face-to-face treatment as part of their anxiety symptoms were offered to take part in the telehealth Internet-based program (TELE, $N$ $=45)$. The rest of patients $(N=40)$ were randomly assigned to an in-person cognitive-behavioral therapy group (CBT, $n=20$ ) or a control group $(C G, n=20)$. From the initial sample of 45 patients, 25 accepted to participate in the TELE group and 14 completed at least 8 sessions. Fiffeen patients completed at least 8 sessions in the CBT group and 15 patients in the CG accepted to complete the post-assessment.

This resulted in a final sample of 44 participants. Table 1 shows the distribution of the sample according to socio-demographic variables. As can be observed, most participants had a history of agoraphobia with panic disorder, were female, and were around 40 years of age. Approximately half of them were married (the rest were single or divorced).

\begin{tabular}{|l|c|cc|}
\hline & GROUPS & & CG \\
\hline Variables & TELE & CBT & $10 / 5$ \\
With / without panic & $9 / 5$ & $9 / 6$ & 10 \\
Gender (female) & 11 & 12 & 39.44 (9.27) \\
Mean age (SD) & $43.8(11.35)$ & 39.11 (10.11) & 8 \\
Married & 6 & 8 & \\
\hline Note. TELE $=$ Internet-based program; CBT = Cognitive-behavioral therapy; CG = Control; SD = Standard Deviation.
\end{tabular}




\section{- INSTRUMENTS}

To verify the diagnosis of agoraphobia, we used the questions about phobias and panic disorder of the Composite International Diagnostic Interview (CIDI), Version 2.1 . The CIDI is a structured interview designed to assess mental disorders according to the criteria established by the ICD-10 (Kessler \& Ustün, 2004). Also, to identify inclusion / exclusion criteria, a semistructured interview were conducted.

The following questionnaires and scales were used as dependent variables (outcome measures) to measure clinical symptoms and therapeutic progress:

\section{a) Agoraphobic Cognitions Questionnaire} (ACQ). The ACQ (Chambless, Caputo, Bright, \& Gallagher, 1984) assesses the catastrophic thoughts that occur when individuals experience anxiety using a 5-point Likert scale. The authors have reported adequate internal consistency $(\alpha=.80)$, high test-retest stability $(r=.86)$, and a one-factor solution. The total score discriminates between patients with agoraphobia and a normal control sample.

b) Body Sensations Questionnaire (BSQ). The BSQ (Chambless et al., 1984) is a self-report questionnaire composed of 17 items about physical sensations when experiencing anxiety, rated on a 5-point Likert scale. The authors have reported high internal consistency $(\alpha=.87)$ and moderate test-retest stability $(r=.67)$, and the scale discriminates between patients with agoraphobia and a normal control sample.

c) Liebowitz Social Anxiety Scale (LSAS). The LSAS (Liebowitz, 1987) is a Likert scale designed to assess the severity of social anxiety disorder. The scale is composed of 24 items assessed from two approaches: 1) fear experienced by the patient in social situations (LSAS-fear); and 2) the degree of avoidance of such situations (LSAS-avoidance). The scales have obtained high alpha coefficients (.92 for LSAS-fear; .92 for LSAS-avoidance; and .96 for the total score) and shown adequate treatment sensitivity, with the following effect sizes: .65 for LSAS-fear; .67 for LSAS-avoidance; and .67 for the total score (Heimberg et al., 1999). In this study, this scale was also used as a mobility scale. d) Beck Depression Inventory-II (BDI-II; Beck, Steer, \& Brown, 1996). This is the second version of a 21 -item inventory developed to assess depression severity. The BDI-II has shown high internal consistency, with alpha coefficients greater than .90 (Beck et al., 1996). This inventory has also exhibited adequate sensitivity and specificity coefficients for detecting depressive disorders (Arnau, Meagher, Norris, \& Bramson, 2001).

\section{- DESIGN}

A multi-group experimental design with pre-post measures was used. Treatment modality was used as an independent variable, with three levels: TELE Internet-based intervention program group, CBT face-to-face treatment group, and Control group.

The CBT program consisted of 11 individual clinical sessions that lasted 30-45 minutes each (provided by a female clinical psychologist). The first three sessions consisted of a psychoeducational session and two training sessions in cognitive restructuring (e.g. identifying phobic scenarios, deactivating strategies, detecting cognitive distortions, changing nonadaptive thoughts). In sessions 4 to 11, patients in the CBT groups were encouraged to confront phobic environments with in vivo exposure using both a stepwise strategy and trained cognitive strategies. After each in vivo exposure, patients completed a self-monitoring sheet. The content of the sheet was discussed in the following session.

The contents of the TELE program were similar to those of the CBT, with some adjustments: seven virtual phobic scenarios (i.e. an airport building and an airplane, a square and a street, an elevator and an underground car park, a bank office, a highway, a beach, and a cableway (Peñate, Roca-Sánchez, Pitti-González, et al., 2014) were provided to practice exposure sessions. Patients could only go to the following session once they had completed the previous one; however, they could go back to previous sessions as necessary. There had to be an interval of at least 48 hours between sessions (to facilitate the exposure task). Questionnaires, inventories (pre-post) and selfmonitoring sheets were made available through the Internet website (doctoragora.com/demo/) or by e-mail. Patients could ask any questions they had using those procedures. 
The doctoragora.com/demo/ website (Figure 1 shows its home page) is well accepted by both agoraphobia patients and clinicians considering the following factors: accessibility, operability, comprehension, learning, and satisfaction (Roca-Sánchez, Álvarez-Pérez, \& Peñate, 2014).

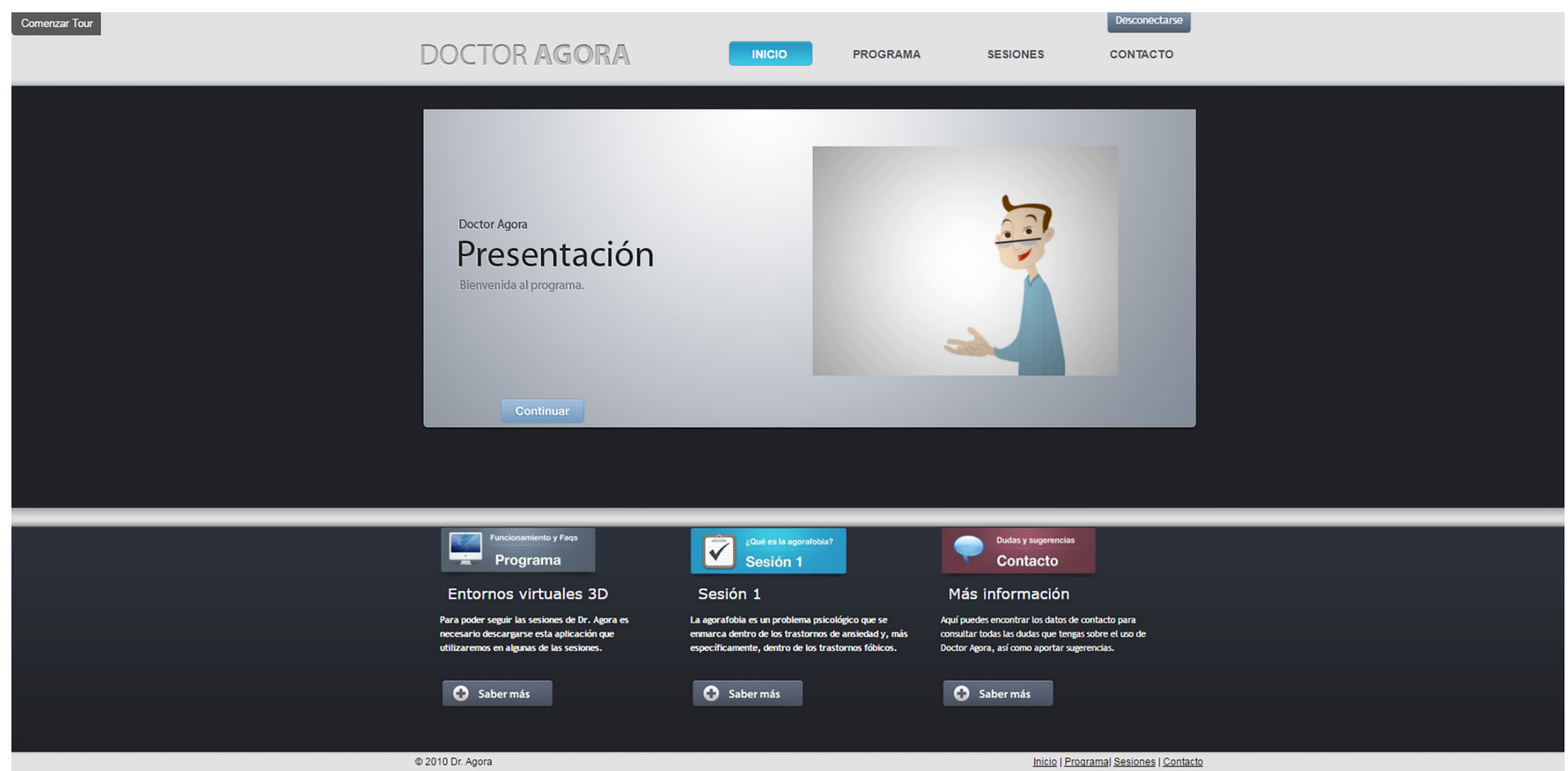

Figura 1. Home page of the doctoragora.com/demo website.

The control group did not receive any treatment and remained in contact with our staff. When the CBT group had finished the treatment program, CG patients were assessed at post-test and given the possibility to complete the CBT program free of charge.

All patients were receiving psychopharmacological treatment with paroxetine or venlafaxine. Paroxetine doses ranged between 20 and $30 \mathrm{mg} /$ day, and venlafaxine doses ranged between 37.5 and 75 $\mathrm{mg} /$ day.

The following variables were used as dependent measures: agoraphobic cognitions, bodily anxiety sensations, fear of social situations, social avoidance, and level of depression.

\section{- PROCEDURE}

In the TELE group, the following procedure was used: once patients had been informed by their psychiatrist or clinical psychologist about the Internet-based program, those who initially agreed were contacted (by telephone or e-mail). Patients were required to come to our office, were a (female) clinical psychologist verified the agoraphobia diagnosis and the rest of the inclusion criteria. At that stage, if they agreed to participate, they signed the informed consent form and were given a username and a password to doctoragora.com/demo/. Additional information was also provided about the website and computer requirements.

In the CBT and CG groups, the procedure was as follows: patients were informed by their psychiatrist or clinical psychologist about the psychological intervention program. Patients who initially agreed were required to come to our department and proceed as with the TELE group for the inclusion criteria. Once they had signed the informed consent form, they were randomly assigned to the CBT or Control groups. Treatment (in the TELE and CBT groups) was considered finished once patients had completed at least eight sessions (when they spend, at least, five exposure sessions).

\section{- DATA ANALYSIS}

Several statistical analyses were conducted 
to compare the three experimental groups (ANOVAs) and to compare pre-post measures (t-tests). When appropriate, the Bonferroni test was applied to identify specific differences between the three groups. The chi-square test was used to compare attrition rates. Because dropout rates, intention-to-treat analyses were conducted using the last-observation-carried-forward method.

\section{RESULTS}

First, we considered the dropouts in each experimental group. In the TELE group, 25 patients started the program and 14 completed at least eight sessions. In the CBT group, 20 patients started the program and 15 finished it (also, at least eight sessions). Statistical data showed that the TELE group had significantly higher dropout rates $\left[X^{2}(1)=15.56 ; p=.000\right]$.
Most of patients in TELE group left the program by an implicit disinterest (they were prolonging the temporal interval among sessions, till they did not connect anymore). As a second reason, some of them showed their preference for a combined use with face-to-face therapy (or via internet, as skype). Finally, few patients said they really were not interested in the program.

We conducted an initial comparison of patients' pre-treatment scores on the outcome measures. Table 2 summarizes the data extracted from an ANOVA comparing the four treatment groups. As can be observed, there were no differences between them at pre-intervention time. Despite we expect TELE group would exhibit higher scores (because patients in this group were classified as having a more severe anxiety disorder), these data showed that all groups were comparable in agoraphobia and depression measures at the initial stage.

Tabla 2

ANOVA of outcome measures comparing pre-intervention scores for the three groups.

\begin{tabular}{|c|c|c|c|c|c|}
\hline VARIABLES & GROUPS & $n$ & $M(S D)$ & $F$ & $p$ \\
\hline \multirow{3}{*}{$\mathrm{ACQ}$} & TELE & 14 & 37.71 (11.45) & \multirow{3}{*}{2.05} & \multirow{3}{*}{.11} \\
\hline & СВT & 15 & 33.06 (1 1.89) & & \\
\hline & CG & 15 & $29.27(7.69)$ & & \\
\hline \multirow{4}{*}{ BSQ } & TELE & 14 & 52.64 (12.97) & \multirow{3}{*}{.24} & \multirow{3}{*}{.86} \\
\hline & CBT & 15 & $53.40(15.16)$ & & \\
\hline & CG & 15 & $50.73(9.86)$ & & \\
\hline & TELE & 14 & 25.07 (13.91) & \multirow{3}{*}{1.44} & \multirow{3}{*}{.24} \\
\hline \multirow{2}{*}{ SAF } & СBT & 15 & $33.47(16.61)$ & & \\
\hline & CG & 15 & 27.40 (12.36) & & \\
\hline \multirow{5}{*}{ SAA } & TELE & 14 & $21.93(16.77)$ & \multirow{4}{*}{1.14} & \multirow{4}{*}{.33} \\
\hline & CBT & 15 & $31.60(17.73)$ & & \\
\hline & & & & & \\
\hline & CG & 15 & $25.73(14.95)$ & & \\
\hline & TELE & 14 & $26.50(12.06)$ & .73 & .53 \\
\hline \multirow[t]{2}{*}{ BDI } & CBT & 15 & $26.20(11.85)$ & \multirow[b]{2}{*}{.73} & \multirow[b]{2}{*}{.53} \\
\hline & & & & & \\
\hline
\end{tabular}

Note. TELE = Telehealth; CBT = Cognitive-behavioral therapy; $C G=$ Control group; $A C Q=$ Agoraphobia cognitions; BSQ = Body sensations, SAF = Social situations, fear; $S A A=$ Social situations, avoidance; BDI = Depression; $M=$ Mean; $S D=$ Standard Deviation; $F=F$ distribution; $p=$ probability. 
In order to identify pre-post treatment effects separately, t-tests for related samples were performed.
Table 3 summarizes the main data for each treatment/control group according to the outcome measures.

Tabla 3

T-test comparisons between pre-post intervention scores on outcome measures in each treatment group.

\begin{tabular}{|c|c|c|c|c|c|c|c|c|c|}
\hline VARIABLES & GROUPS & $n$ & M-pre & $S D$ & M-post & $S D$ & $t$ & $p$ & $d$ \\
\hline \multirow{3}{*}{$A C Q$} & TELE & 14 & 37.71 & 11.45 & 36.57 & 12.65 & .60 & .56 & .16 \\
\hline & CBT & 15 & 33.06 & 11.89 & 22.06 & 6.19 & 4.49 & .00 & .77 \\
\hline & CG & 15 & 29.27 & 7.69 & 36.13 & 7.91 & -2.65 & .01 & .58 \\
\hline \multirow{3}{*}{ BSQ } & TELE & 14 & 52.64 & 12.97 & 46.86 & 14.00 & 2.28 & .04 & .53 \\
\hline & CBT & 15 & 53.40 & 15.16 & 38.87 & 12.22 & 4.37 & .00 & .76 \\
\hline & CG & 15 & 50.73 & 9.86 & 57.21 & 11.31 & -1.40 & .18 & .35 \\
\hline \multirow{3}{*}{ SAF } & TELE & 14 & 25.07 & 13.91 & 25.36 & 12.54 & -12 & .90 & .03 \\
\hline & CBT & 15 & 33.47 & 16.61 & 22.73 & 16.45 & 3.90 & .00 & .72 \\
\hline & CG & 15 & 27.40 & 12.36 & 32.76 & 18.63 & -1.03 & .31 & .27 \\
\hline \multirow{3}{*}{ SAA } & TELE & 14 & 21.93 & 16.77 & 21.07 & 15.78 & .60 & .55 & .16 \\
\hline & СBT & 15 & 31.60 & 17.73 & 21.53 & 16.81 & 3.00 & .01 & .63 \\
\hline & $C G$ & 15 & 25.73 & 14.95 & 33.86 & 18.56 & -1.66 & .12 & .26 \\
\hline \multirow{3}{*}{ BDI } & TELE & 14 & 26.50 & 12.06 & 18.71 & 7.03 & 2.74 & .05 & .61 \\
\hline & CBT & 15 & 26.20 & 11.85 & 13.61 & 7.51 & 4.43 & .00 & .76 \\
\hline & CG & 15 & 21.87 & 7.79 & 23.20 & 11.05 & -1.69 & .11 & .41 \\
\hline
\end{tabular}

Note. TELE = Telehealth; CBT = Cognitive-behavioral therapy; CG = Control group; $\mathrm{ACQ}=$ Agoraphobia cognitions; $\mathrm{BSQ}=\mathrm{Body}$ sensations, SAF = Social situations, fear; $S A A=$ Social situations, avoidance; $B D I=$ Depression; $M=$ Mean; $S D=$ Standard Deviation; $\dagger=$ Student's $t$; $p=$ probability; $\mathrm{d}=$ Cohen's $\mathrm{d}$.

There was clearly a treatment condition that was associated with an overall improvement. The CBT group improved in all five measures, with a decrease from the initial symptoms of anxiety and depression. The telehealth group improved in two measures: body sensations and depression level. In this pre-post comparison, the control group differed in one measure: agoraphobic cognition, which was worse in this group, as patients in this group had higher scores on this variable. The rest of the variables were not significant.

To analyze pre-post-treatment effects, differential scores were subjected to an ANOVA. These differential scores were obtained by subtracting the pre-treatment score from the post-treatment score. As shown on Table 4, there were significant differences in all five outcome measures, with medium/large effect sizes. Overall, there were negative differential scores, which means a decrease in anxiety/depression levels. This did not apply to control groups: differences were positive in all five variables, pointing to a deterioration of development in those variables. 


\begin{tabular}{|c|c|c|c|c|c|c|c|c|c|}
\hline VARIABLES & GROUPS & $n$ & $\begin{array}{l}\text { Post- } \\
\text { pre- }\end{array}$ & minus & $S D$ & $F$ & $p$ & $n^{2}$ & Bonferroni \\
\hline \multirow{3}{*}{$\mathrm{ACQ}$} & TELE & 14 & -1.14 & & 7.19 & \multirow{3}{*}{12.28} & \multirow{3}{*}{.00} & \multirow{3}{*}{.40} & CBT > TELE, \\
\hline & CBT & 15 & -11.00 & & 9.48 & & & & $C G$ \\
\hline & $C G$ & 15 & 6.87 & & 9.38 & & & & TELE $>C G^{*}$ \\
\hline \multirow{3}{*}{$B S Q$} & TELE & 14 & -5.79 & & 9.50 & \multirow{3}{*}{10.66} & \multirow{3}{*}{.00} & \multirow{3}{*}{.36} & \multirow{3}{*}{$\begin{array}{l}\mathrm{CBT}>\mathrm{CG} \\
\mathrm{TELE}>\mathrm{CG}\end{array}$} \\
\hline & CBT & 15 & -14.53 & & 12.88 & & & & \\
\hline & $C G$ & 15 & 6.47 & & 8.58 & & & & \\
\hline \multirow{3}{*}{ SAF } & TELE & 14 & .29 & & 9.19 & \multirow{3}{*}{3.24} & \multirow{3}{*}{.02} & \multirow{3}{*}{.15} & \multirow{3}{*}{$\mathrm{CBT}>\mathrm{CG}$} \\
\hline & CBT & 15 & -10.73 & & 10.67 & & & & \\
\hline & CG & 15 & 5.27 & & 20.58 & & & & \\
\hline \multirow{3}{*}{ SAA } & TELE & 14 & -.86 & & 5.35 & \multirow{3}{*}{3.82} & \multirow{3}{*}{.01} & \multirow{3}{*}{.17} & \multirow{3}{*}{$\mathrm{CBT}>\mathrm{CG}$} \\
\hline & CBT & 15 & -10.07 & & 12.99 & & & & \\
\hline & CG & 15 & 8.13 & & 19.69 & & & & \\
\hline \multirow{3}{*}{ BDI } & TELE & 14 & -7.79 & & 9.31 & \multirow{3}{*}{8.19} & \multirow{3}{*}{.00} & \multirow{3}{*}{.31} & \multirow{3}{*}{$\begin{array}{l}\mathrm{CBT}>\mathrm{CG} \\
\mathrm{TELE}>\mathrm{CG}\end{array}$} \\
\hline & СВT & 15 & -12.60 & & 11.01 & & & & \\
\hline & CG & 15 & 7.33 & & 14.86 & & & & \\
\hline
\end{tabular}

According to the Bonferroni tests, differences were as follows: again, CBT was the most effective treatment. Patients in this group exhibited a significant improvement in agoraphobic cognition compared to the other groups. They also obtained better results in body sensation compared to the control group. CBT was the only group that showed a significant improvement in social phobia (in both fear and avoidance scores) compared to the control group. Patients in the TELE group obtained better results in depression, body sensation, and agoraphobic cognition (a slight difference) compared to the no-treatment group. The TELE group did not differ from the CBT group in body sensation or depression level.

\section{DISCUSSION}

In this study we attempted to provide empirical evidence of the efficacy of an Internet computer-based treatment (ICT) for agoraphobia with minimal in-person contact between therapist and patient. Therapist contact is one of the most remarkable variables associated with the efficacy of ICTs (Baumeister et al., 2014; Newman et al., 2011; Peñate \& Fumero, 2016). Yet, paradoxically, this fact represents the first critical aspect of ICTs, because there is usually a lack of control of therapist contact (e.g. frequency, time, scheduled vs. requested). In fact, this may affect the internal validity of ICTs at least in two ways: (i) not all ICTs are comparable because they may significantly differ in therapist contact; and (ii) excessive in-person contact is against 
the nature of ICTs. In an extreme version, when there is frequent therapist contact, the treatment can be understood as an in-person intervention supported by Internet treatment tools.

A second critical aspect is the fact that the efficacy of ICTs is greater than no treatment and is sometimes greater than in-person treatment (Andersson et al., 2014; van Ballegooijen et al., 2014). The reasons why ICT interventions are sometimes better than direct treatment are not well explained. This apparent illogical result needs to be verified with a better experimental design given that, when an ICT is compared to a direct intervention, both treatment programs are not usually matched (Newman et al., 2011).

In this study we attempted to answer these critical questions in the following way: First, we limited therapist contact to minimal initial diagnosis contact (about one hour); all other contacts were conducted over the Internet, (i.e. by e-mail). Second, the in-person treatment group was matched to the ICT group (e.g., number of sessions, duration, therapeutic strategies).

Results clearly showed a better efficacy of in-person CBT treatment. Improvements were observed in all outcome measures used and the CBT group exhibited lower attrition rates (van Ballegooijen et al., 2014). Patients in the ICT group also showed improvements in the comparisons between pre-post scores, and compared to the control group (in body sensations and depression level). No differences with the CBT group were found in body sensations, social phobia, or depression. Taking the results as a whole, the ICT showed some level of efficacy, but a matched in-person treatment exhibited better results. Moreover, it is interesting to note that the ICT group exhibited better results than the control group especially because the notreatment group was becoming worse at postmeasure. Consequently, ICTs prevent patient deterioration.

The efficacy of ICTs regarding depression level is an outstanding finding given that the program does not deal with affective symptoms directly (and results cannot be entirely ascribed to the effects of antidepressants, since the CG did not improve). An explanation could be that patients in the ICT group considered this program as an opportunity to improve their avoidance symptoms (since these patients were especially affected by such symptoms).
This study has several limitations. The first one is its sample size: larger samples are needed to reach solid conclusions. Moreover, assignment was not completely random, so we can suspect that patients in the TELE group had more severe symptoms. Fortunately, pre-treatment comparison data did not support this idea. An explanation of this result could be to the fact that we consider severe agoraphobia when patients showed difficulties or they refused to a face-to-face treatment. Perhaps this symptom represents a part of severity, but it is not the unique criterion. Another limitation was the fact that the ITC program established a minimum interval of 48 hours but not a maximum period of time between sessions, and several patients accessed the program once a week, which affected the necessary continuity of treatment. Furthermore, although patients recorded their exposure exercises (using self-monitoring sheets), an actual test of in vivo exposure (such as a behavioral avoidance test or mobility test) may improve external validity. A fourth limitation was the absence of follow-up data.

Future researches are needed to integrate all data supporting telehealth implementations: differential therapeutic utility, technology procedures, economic feasibility, legislation and ethics. The final results could be the existence of clear scientific guidelines for its clinical practice.

With this study, the main contributions to such guidelines are the following conclusions: an ICT program with minimal patient-therapist contact can be a useful tool when compared to the absence of treatment, but it is far from reaching the efficacy of an in-person intervention. ICTs can represent an opportunity for patients to see an improvement in their symptoms and may therefore play a role in motivating them to receive in-person therapy or as an adjuvant therapy. In any case, ICTs can be the therapy of choice for patients with severe agoraphobia because of their avoidance symptoms. But, according our data, patients need to be prevented about the clinical efficacy level they can attain with ICT resources.

\section{- Conflict of interest}

The authors declare no conflict of interest.

\section{- Acknowledgments}

This study was supported by the following grants: PSI200909836 and PSI2013-42912-R (Spanish Ministry of Economy and Competitivity). 


\section{REFERENCES}

Alonso, J., Angermeyer, M. C., Bernert, S., Bruffaerts, R., Brugha, T. S., Bryson, H., ... Vollebergh, W. A. M. (2004). Disability and quality of life impact of mental disorders in Europe: Results from the European Study of the Epidemiology of Mental Disorders (ESEMeD) project. Acta Psychiatrica Scandinavica, 109 (s420), 38-46. http://doi.org/10.1111/i.1600-0047.2004.00329.x

Andersson, G., Cuiipers, P., Carlbring, P., Riper, H., \& Hedman, E. (2014). Guided Internet-based vs. faceto-face cognitive behavior therapy for psychiatric and somatic disorders: A systematic review and meta-analysis. World Psychiatry, 13, 288-295. http://doi.org/10.1002/wps.20151

Andersson, G., \& Titov, N. (2014). Advantages and limitations of Internet-based interventions for common mental disorders. World Psychiatry, 13, 4-11. http:// doi.org/10.1002/wps.20083

Arnau, R. C., Meagher, M. W., Norris, M. P., \& Bramson, R. (2001). Psychometric evaluation of the Beck Depression Inventory-II with primary care medical patients. Health Psychology, 20, 112-119. http://doi.org/10.1037//0278-6133.20.2.112

Baumeister, H., Reichler, L., Munzinger, M., \& Lin, J. (2014). The impact of guidance on Internetbased mental health interventions - A systematic review. Internet Interventions, 1, 205-215. http://doi.org/10.1016/i.invent.2014.08.003

Beck, A., Steer, R., \& Brown, G. (1996). Manual for the Beck Depression Inventory-II. San Antonio, Texas: Psychological Corporation.

Bergström, J., Andersson, G., Liótsson, B., Rück, C., Andréewitch, S., Karlsson, A., ... Lindefors, N. (2010). Internet-versus group-administered cognitive behaviour therapy for panic disorder in a psychiatric setting: A randomised trial. BMC Psychiatry, 10, 54. http://doi.org/10.1186/1471-244X-10-54

Carlbring, P., Nilsson-lhrfelt, E., Waara, J., Kollenstam, C., Buhrman, M., Kaldo, V., ... Andersson, G. (2005). Treatment of panic disorder: Live therapy vs. self-help via the Internet. Behaviour Research and Therapy, 43, 1321 1333. http://doi.org/10.1016/i.brat.2004.10.002

Chambless, D. L., Caputo, G. C., Bright, P., \& Gallagher, R. (1984). Assessment of fear of fear in agoraphobics: The Body Sensations Questionnaire and the Agoraphobic Cognitions Questionnaire. Journal of Consulting and Clinical Psychology, 52, 1090-1097. http://doi.org/10.1037/0022-006X.52.6.1090

Davies, E. B., Morriss, R., \& Glazebrook, C. (2014). Computer-delivered and web-based interventions to improve depression, anxiety, and psychological well- being of university students: A systematic review and meta-analysis. Journal of Medical Internet Research, 16 (5), e130. http://doi.org/10.2196/imir.3142

Foroushani, P. S., Schneider, J., \& Assareh, N. (2011). Meta-review of the effectiveness of computerised CBT in treating depression. BMC Psychiatry, 11, 131. http:// doi.org/10.1186/1471-244X-11-131

Heimberg, R. G., Horner, K. J., Juster, H. R., Safren, S. A., Brown, E. J., Schneier, F. R., \& Liebowitz, M. R. (1999). Psychometric properties of the Liebowitz Social Anxiety Scale. Psychological Medicine, 29, S0033291798007879.

http://doi.org/10.1017/S0033291798007879

Kessler, R. C., Petukhova, M., Sampson, N. A., Zaslavsky, A. M., \& Wittchen, H.-U. (2012). Twelve-month and lifetime prevalence and lifetime morbid risk of anxiety and mood disorders in the United States. International Journal of Methods in Psychiatric Research, 21, 169. 184. http://doi.org/10.1002/mpr. 1359

Kessler, R. C., \& Ustün, T. B. (2004). The World Mental Health (WMH) Survey Initiative Version of the World Health Organization (WHO) Composite International Diagnostic Interview (CIDI). International Journal of Methods in Psychiatric Research, 13, 93-121. Retrieved from http://www.ncbi.nlm.nih.gov/pubmed/15297906

Kiropoulos, L. A., Klein, B., Austin, D. W., Gilson, K., Pier, C., Mitchell, J., \& Ciechomski, L. (2008). Is internet-based CBT for panic disorder and agoraphobia as effective as face-to-face CBT? Journal of Anxiety Disorders, 22, 1273-1284. http://doi.org/10.1016/i.janxdis.2008.01.008

Klein, B., Richards, J. C., \& Austin, D. W. (2006). Efficacy of internet therapy for panic disorder. Journal of Behavior Therapy and Experimental Psychiatry, 37, 213 238. http://doi.org/10.1016/i.jbtep.2005.07.001

Krupinski, E., \& Weinstein, R. (2014). Telemedicine, Telehealth and m-Health: New Frontiers in Medical Practice. Healthcare, 2, 250-252. http://doi.org/10.3390/healthcare2020250

Kyrios, M., \& Thomas, N. (2014). Psychology and the Internet: Where are we and where to from here? InPsych, 36 (3), 8-11.

Liebowitz, M. R. (1987). Social phobia. In D. F. Klein (Ed.), Anxiety: Modern problems in pharmacopsychiatry (pp. 141-173). New York: Karger.

Moral, M. V., \& Suárez, C. (2016). Factores de riesgo en el uso problemático de Internet y del teléfono móvil en adolescentes españoles [Risk factors in the problematic use of Internet and phone in Spanish adolescents]. Revista Iberoamericana de Psicología y Salud, 7, 69-78. http://doi.org/10.1016/i. rips.2016.03.001 
Newman, M. G., Szkodny, L. E., Llera, S. J., \& Przeworski, A. (2011). A review of technology-assisted self-help and minimal contact therapies for anxiety and depression: Is human contact necessary for therapeutic efficacy? Clinical Psychology Review, 31, 89-103. http://doi.org/10.1016/i.cpr.2010.09.008

Peñate, W. (2012). About the effectiveness of telehealth procedures in psychological treatments. International Journal of Clinical and Health Psychology, 12, 475487.

Peñate, W., \& Fumero, A. (2016). A meta-review of Internet computer-based psychological treatments for anxiety disorders. Journal of Telemedicine and Telecare, 22 (1), 3-11. http://doi.org/10.1177/1357633X15586491

Peñate, W., Roca-Sánchez, M. J., \& Pino-Sedeño, T. (2014). Los nuevos desarrollos tecnológicos aplicados al tratamiento psicológico. [New technological developments applied to psychological treatment]. Acta Colombiana de Psicología, 17, 91-101.

Peñate, W., Roca-Sánchez, M. J., Pitti-González, C. T., Bethencourt, J. M., de la Fuente Portero, J. A., \& Gracia, R. (2014). Cognitive-behavioral treatment and antidepressants combined with virtual reality exposure for patients with chronic agoraphobia. International Journal of Clinical and Health Psychology, 14, 9-17. http://doi.org/10.1016/S1697-2600(14)70032-8

Richards, D., \& Richardson, T. (2012). Computer-based psychological treatments for depression: A systematic review and meta-analysis. Clinical Psychology Review, 32, 329-342. http://doi.org/10.1016/i. cpr.2012.02.004
Roca-Sánchez, M. J., Álvarez-Pérez, Y., \& Peñate, W. (2014). Aceptabilidad de un tratamiento vía internet para la agorafobia por pacientes y terapeutas. Análisis y Modificación de Conducta, 40 (161-162), 29-41. Van Ballegooijen, W., Cuijpers, P., van Straten, A., Karyotaki, E., Andersson, G., Smit, J. H., \& Riper, H. (2014). Adherence to internet-based and face-toface cognitive behavioural therapy for depression: A meta-analysis. PLOS ONE, 9, el00674. http://doi.org/10.1371/journal.pone.0100674

Vázquez, F. L., Torres, Á., Blanco, V., Otero, P., \& Hermida, E. (2015). Intervenciones psicológicas administradas por teléfono para la depresión: Una revisión sistemática y meta-análisis [Telephone-administered psychological interventions for depression: A systematic review and meta-analysis]. Revista Iberoamericana de Psicología y Salud, 6, 39-52. http://doi.org/10.1016/S2171-2069(15)70005-0

Wittchen, H.-U., Gloster, A. T., Beesdo-Baum, K., Fava, G. A., \& Craske, M. G. (2010). Agoraphobia: $A$ review of the diagnostic classificatory position and criteria. Depression and Anxiety, 27, 113-133. http:// doi.org/10.1002/da.20646

World Health Organization. (1992). ICD-10: International Statistical Classification of Diseases and Related Health Problems. Geneve, Switzerland: World Health Organization. 